\title{
POR UMA ESTÉTICA MUNDIAL-LITERÁRIA DA MEMÓRIA PÓS-COLONIAL: RAINHAS DA NOITE DE JOÃO PAULO BORGES COELHO'
}

\section{TOWARDS A WORLD-LITERARY AESTHETICS OF POSTCOLONIAL MEMORY: RAINHAS DA NOITE, BY JOÃO PAULO BORGES COELHO}

Emanuelle Santos

${ }^{1}$ Versão em português inédita, revisada e expandida do ensaio: "Towards a World-Literary Aesthetics of Postcolonial Memory: Rainhas da Noite, by João Paulo Borges Coelho". In Brugioni, E., Grosseguesse, O., Medeiros, P., A companion to João Paulo Borges Coelho: Rewriting the (post)colonial remains. Oxford: Peter Lang, 2020. Traduzido pela autora.

Via Atlântica, São Paulo, n. 40, p. 333-363, nov. 2021. doi: 10.11606/va.i40.174344 
Resumo: Com foco na inerente relação entre as esferas locais e globais que marca a ficção de João Paulo Borges Coelho, este ensaio propõe que a articulação estética da memória pós-colonial presente em sua obra constituída como literatura-mundial. Através da análise do romance Rainhas da Noite (2013), argumentamos que sua representação nuançada do colonialismo pela lente da memória opera uma crítica das sociedades pós-coloniais que é, intrinsecamente, transnacional e sistêmica.

Palavras-chave: literatura-mundial, memória pós-colonial, João Paulo Borges Coelho. 
Abstract: This article discusses the ways in which João Paulo Borges Coelho's widely acknowledged talent creating literary works that conjugate global issues and local contexts illuminates the connection between postcolonial memory and world-literature. Through an analysis of this 2013 novel Rainhas $d a$ Noite, we argue that his nuanced representation of colonialism through memory operates a critique of postcolonial societies that is inherently transnational and systemic.

Keywords: world-literature, postcolonial memory, João Paulo Borges Coelho. 
O diálogo entre literatura e historiografia são características da ficção de João Paulo Borges Coelho já amplamente estudadas pelos críticos de sua obra. Um crescente número de livros, ensaios e artigos publicados dentro e além do espaço transnacional formado pelos países de língua oficial portuguesa vem mapeando com sucesso as várias formas através das quais o trabalho do autor evoca aspectos do mosaico humano, geográfico, social e histórico que formam Moçambique. Ainda que a pujança desta mistura entre história e literatura na obra de Borges Coelho possa ser - e frequentemente seja - atribuída ao fato de o autor possuir formação profissional como historiador, é sua habilidade no âmbito do ofício literário que o permite articular e disseminar uma ampla gama de aspectos menos conhecidos das sociedades moçambicanas. ${ }^{2}$ Esta frutífera aliança entre diferentes formas de conceber o mundo, que conjuga uma visão histórica de Moçambique dentro do sistema-mundial (WALLERSTEIN, 1974) e a estética do romance, confere à obra de Borges Coelho um potencial crítico que excede o âmbito nacional da memória cultural. Tal como argumentaremos neste ensaio, sua reescrita ficcional da história através da memória constitui

\footnotetext{
${ }^{2}$ Nas palavras de Borges Coelho: "os meus textos académicos têm sempre um 'deslize' literário [...] e, por outro lado, a minha literatura dificilmente existiria sem a história e a geografia. 0 meu primeiro romance partiu directamente de anotações para um texto académico." (BORGES COLEHO, 2008, p.233)
} 
uma importante elaboração estética mundial-literária da memória pós-colonial.

Falar de uma literatura-mundial da memória pós-colonial, especialmente uma que emerge no espaço periférico de Moçambique, é rejeitar a suposição corrente de que literatura-mundial e estudos pós-coloniais são paradigmas que se opõe. Ao contrário do que afirmam críticos em ambos os lados da fissura ideológica quanto à celebração ou crítica do capitalismo global, o paradigma da literatura-mundial não emerge como resultado inevitável da recusa dos estudos pós-coloniais em se posicionar quanto ao assunto. 0 crescimento e a popularização dos estudos pós-coloniais até o presente reúne toda uma gama de contribuições que atestam o seu potencial crítico de ambas posições. Com uma metodologia dedicada à identificação, exposição e crítica de hegemonias econômicas e culturais, bem como de dominação e desigualdade, os estudos pós- coloniais seguem unicamente equipados para mostrar justamente como tanto anti-capitalismo como globalismo retêm importante funções críticas quando aplicados estrategicamente à situações específicas em termos de tempo e espaço. Desta maneira, no âmbito de sociedades tais como as dos países africanos de língua oficial portuguesa, que no curto período dos últimos 50 anos passaram pelo colonialismo, socialismo, neocolonialismo, e por pro- 
cessos de neoliberalização, a lente dos estudos pós-coloniais tem nos ajudado a compreender criações literárias que criticam tanto o capitalismo como o socialismo enquanto práxis. Assim, o surgimento do paradigma da literatura-mundial não se deve à "falha" dos estudos pós-coloniais em "dar conta das mudanças históricas num sistema-mundial característico do capitalismo tardio" (GRAHAM ET AL, 2012, p.465; tradução nossa), mas sim à sua capacidade de evoluir especificamente para tratar das mudanças históricas vividas por sociedades pós-coloniais na longue durée do sistema-mundial capitalista.

Deste modo, a representação de características sistêmicas das várias mudanças históricas pelas quais passou Moçambique no último século eleva a leitura que Borges Coelho faz da memória pós-colonial de seu país à literatura-mundial, pois transforma em matéria romanesca a desigualdade subjacente à relações socio-históricas que são, simultaneamente, domésticas e transnacionais. A definição de "literatura-mundial" (or world-literature no original em inglês) empregada nesse ensaio é aquela cunhada pelo Coletivo de Pesquisa de Warwick (Warwick Research Collective - WReC) em Desenvolvimento Combinado e Desigual - Por uma Nova Teoria da Literatura-Mundial (livro publicado em 2015 e traduzido para a língua portuguesa em 2020), que não deve ser confun- 
dida com o conceito de "literatura-mundo" (ou world literature no original em inglês) cunhado por David Damrosh em What is World Literature? (2003, sem tradução disponível). Enquanto que, para Damrosch "uma obra se transforma em literatura-mundo por um processo duplo: primeiro, por ser lida como literatura; segundo, por circular num mundo mais amplo, além do seu ponto de origem linguístico e cultural" (2003, p.6; grifos do autor, tradução nossa), para o WreC literatura-mundial (em inglês world-literatu$r e$, necessariamente com hífen diferenciando-se do conceito de Damrosch e aproximando-se do conceito de sistema-mundial de Wallerstein) é "uma categoria analítica, não uma centrada em julgamento estético" (2015, p.49; tradução nossa) ${ }^{3}$. Para o coletivo de autores, uma obra da literatura-mundial é aquela cuja forma e conteúdo refletem um " um sistema-mundial

\footnotetext{
${ }^{3}$ A diferença conceitual na abordagem do WReC e de Damrosch é expressa pela importante presença (ou ausência) do hífen entre as palavras world e literature nas suas respectivas formulações teóricas em inglês. Para trazer essa diferença conceitual à presente formulação em português, a autora deste ensaio traduz o conceito world literature de Damrosch como literatura-mundo, alinhando essa perspectiva à de Helena Carvalhão Buesco em Experiência do incomum e boa vizinhança: Literatura comparada e literatura-mundo (2013), e o conceito de world-literature elaborado pelo WReC como literatura-mundial, em linha com a tradução do livro publicada em 2020 pela Editora da Unicamp. Assim, enquanto a diferença em inglês é expressa pelo hífen, em português essa diferença conceitual é expressa pelo uso de mundo ou mundial.
} 
único, mas radicalmente desigual; uma única modernidade, combinada e desigual" (2015, p.49; tradução nossa). Esta perspectiva abrange as peculiaridades da condição pós-colonial tal como vivida por diversas sociedades moçambicanas, cujo contínuo diálogo com as heranças do colonialismo - outra face do sistema-mundial capitalista em sua longue durée - revela uma história de desigualdade sistêmica, e portanto simultaneamente local e global. Ainda que a obra de João Paulo Borges Coelho preencha os critérios de Damrosch para ser considerada literatura-mundo, dado que ela circula muito além da sua cultura e língua de origem como literatura, é naquilo que constitui literatura-mundial que o potencial crítico da obra do autor pode ser apreciado plenamente, tal como a análise do seu romance Rainhas da Noite de 2013 demonstra.

O colonialismo narrado como parte do sistema-mundial

Rainhas da Noite começa na Maputo atual quando um narrador anônimo recebe um misterioso caderno manuscrito de um vendedor de livros itinerante como prêmio de consolação por não ter conseguido barganhar o preço de uma edição ilustrada de $A$ Ilha de Próspero (1972) de Rui Knopfli. Na medida em que a narrativa se desenvolve o leitor aprende que o ca- 
derno é, na verdade, o diário pessoal de uma senhora portuguesa branca chamada Maria Eugénia Murilo escrito num período indefinido explicitamente, mas que remete aos anos que antecedem o início da Luta pela Libertação do país. Ela, juntamente com sua filha ainda criança, se muda de Lisboa para a pequena vila moçambicana de Moatize a fim de se juntar ao marido que trabalhava como engenheiro na mineradora belga que então operava na colônia portuguesa. Tendo sido esquecido logo após sua aquisição, o diário volta à atenção do narrador apenas quando, por acaso, ele encontra um dos antigos empregados de Maria Eugénia, Travessa Chassafar, numa repartição pública da capital. Assim, a narrativa que se inicia é constituída por transcrições do dito diário, seguidas pelas anotações acerca de fatos e pessoas mencionadas feitas pelo narrador anônimo, que passa a pesquisar os arquivos governamentais em busca de pistas.

O conteúdo do caderno consiste, em sua maioria, de registros pessoais das dificuldades diárias enfrentadas por mulheres brancas privilegiadas que, confinadas nas gaiolas douradas das casas fornecidas pela mineradora aos seus funcionários de alto escalão, precisam navegar os diversos estratos dos níveis de poder que regem suas vidas. 0 aspecto estratificado dos temas da narrativa é refletido no seu enredo, constituído por um prólogo contando como o diário 
foi adquirido e seguido por nove capítulos numerados, cada um deles dividido em duas partes. No início de cada capítulo temos a transcrição de parte do diário de Maria Eugénia, composto por uma narrativa em primeira pessoa, aparentemente inalterada pela narrador do romance, através da qual acompanhamos suas atividades diárias e suas opiniões. A segunda parte de cada capítulo é intitulada "Notas". Nela, o narrador escreve na sua posição como editor do diário no presente. É nesta parte de cada capítulo que temos as reflexões do narrador sobre os conteúdos do diário que se tornam sua obsessão. É ainda nesta seção que temos o registro dos encontros entre o narrador e Travessa Chassafar, testemunha ocular de muitos dos fatos descritos no diário. Cada capítulo contém ilustrações que são apresentadas como reproduções de fotos encontradas no manuscrito original, enquanto que outras fotos tiradas no presente podem ser encontradas na seção de notas em cada um dos capítulos. Por fim, o livro possui também um epílogo no qual é narrado o último encontro entre o narrador e Chassafar, a quem o diário é finalmente entregue.

A relevância dos temas do romance, escolha de personagens e algumas das peculiaridades de sua forma já foram objetos de análise por críticos da obra do autor. A questão da representação da memória, 
aspecto do romance que tende a ganhar maior atenção, é analisado por Elena Brugioni nas suas implicações para uma reconceptualização do romance histórico (2015, 2017). Já Sandra Sousa (2016), Nazil Can (2017) e Margarida Calafate Ribeiro (2018) atentam para as formas através das quais as mulheres da narrativa negociam com as estruturas de poder durante o período do colonialismo tardio, questionando a separação de pessoas - e personagens - em categorias bem definidas e fechadas tal como é característico da historiografia tradicional. Can, por exemplo destaca que a escolha de uma ótica feminina confere nuances e "pontos cinzentos" (2017, p.187) à narrativa do colonialismo, uma observação que se alinha à perspectiva dos estudos de memória atualmente em voga no campo das literaturas em língua portuguesa. Entretanto, como se é de esperar num romance de tal profundidade, ainda que as mulheres geralmente exerçam papel importante na ficção de Borges Coelho, o protagonismo que esse romance dá à expressão de Maria Eugénia, contando sua própria história e a de outras colonas brancas, bem como a relação dessas mulheres com seus empregados negros num universo regido por conspirações, constitui apenas uma das dimensões através da qual o autor quebra com uma representação tradicional dos papéis fixos desses atores sociais. Igualmente importante é a forma como a narrativa quebra com representações 
clássicas da imiscibilidade de figuras do colonizador e do colonizado sem, com isso, ceder a estereótipos lusotropicalistas. Além disso, a importante presença de personagens de um país que não se insere diretamente na narrativa oficial do colonialismo português, como a da esposa belga do diretor da mineradora estrangeira, Madame Annemarie Simon, coloca o foco do romance nas relações de atores e espaços periféricos como donas-de-casa, empregados domésticos e a complexa esfera do lar, pintando um retrato muito mais detalhado das relações sociais e durante o colonialismo na sua dimensão sistêmica.

No romance, a guerra tácita entre a colona portuguesa e a senhora belga que controla a esfera social da vida dos empregados do alto escalão da empresa, bem como a cumplicidade entre Maria Eugénia e seu empregado, Travessa Chassafar, refletem a complexa, tensa e tênue teia de relações clientelistas das quais Portugal dependia a fim de manter posse e controle de seu vasto território colonial ultramarino. Para além de criar um universo ficcional no qual as conhecidas táticas de subordinação impostas por Portugal às populações de suas colônias - cujo número de pessoas nativas excediam em muitas vezes a de colonos - é amplamente representada, o romance destaca-se por mostrar como essas práticas eram parte de um sistema-mundial no qual o papel do colonizador tam- 
bém era relativo. Assim, Rainhas da Noite retrata os processos de hegemonia e subordinação econômica de escopo sistêmico que obrigava Portugal a negociar, em pé de desigualdade, com outras potências europeias. Dessa forma, a posição de Maria Eugénia na pequena sociedade de Moatize era duplamente marginal visto que devia tanto à sua subordinada posição de mulher num contexto patriarcal, quanto à posição periférica da sua condição de portuguesa, uma vez que o prestígio de seu país como potência global ocupava uma posição marginal à de outros países localizados no centro do sistema-mundial capitalista. A indignação de Maria Eugénia frente à recusa de seu marido de se opor a participar de uma das funções noturnas impostas aos altos funcionários brancos da empresa belga pela esposa do diretor constitui um excelente exemplo do desejos de autodeterminação da colona portuguesa:

Retorqui, já alterada, que a sua subserviência me espantava; mais do que isso, que ela me desapontava profundamente. 0 que acontecera àquele Murilo combativo que conhecera? Já quanto a mim, acrescentei, ele podia ter a certeza de que em mim ninguém mandava!

"Vou se quiser, se não quiser não vou!", concluí, com talvez excessiva agressividade. 
Murilo permaneceu imperturbável. [...] Asseverou que bastava uma palavra minha e ele despedia-se do maldito emprego e regressávamos os três para Lisboa. Se eu dissesse que era isso que me tornava feliz, de imediato tomaria a atitude.

[...]

Senti, na altura, que Murilo me submetia a uma espécie de chantagem. Que faríamos nós em Portugal, onde ele dificilmente acharia um emprego como este? Que faria eu quando tivesse que enfrentar todos os dias a muda cesura do seu olhar, real ou inventada? Virei-lhe as costas e meti-me no quarto, batendo com a porta. (BORGES COELHO, 2013, p.114-116)

A situação de relativa marginalidade de Maria Eugénia, cuja condição de proletariado do capital estrangeiro é mais vantajosa que a de colono português, espelha a do colonialismo português depois da Conferência de Berlim (1884-1885), culminando no Ultimato Britânico (1890) que manchou a imagem internacional de poder ambicionada pelo país. De acordo com Malyn Newitt, "Portugal [...] não podia ser ignorado numa região em que era o único país europeu com uma presença real, entretanto o país tem sido frequentemente representado como um mero coadjuvante na Conferência, tendo suas reivindica- 
ções ignoradas e sua influência desprezada" (2009, p.190; tradução nossa). Depois da conferência, adoção da regra de ocupação efetiva para conferir a posse de territórios africanos à estados europeus expôs ainda mais a fatual situação semiperiférica do país no contexto de europeu. Devido à falta de recursos humanos e financeiros que Portugal enfrentava para manter e explorar suas vastas colônias africana, o país “abriu seus domínios ultramarinos para que companhias estrangeiras investissem na produção e na infraestrutura, assumindo assim um papel secundário em suas próprias colônias, definindo um modelo de colonialismo dependente" (FREIXO, 2007, p.2; grifo do autor). Ainda segundo Freixo, "[d]esta forma, os interesses do capital internacional acabaram gerando uma espécie de 'tolerância' das grandes potências para com a presença portuguesa na África, apesar do clamor geral pela descolonização" (FREIX0, 2007, p.2). Com isso, vê-se que o desdobramento desse modelo econômico e administrativo sistêmico foi, historicamente, essencial para o estabelecimento colonial de Moçambique, mas especialmente importante para a região de Moatize, dadas suas imensas reservas de carvão, um recurso natural primordial para o crescimento industrial dos países desenvolvidos (BATA, 2018). Moatize, assim, constitui o cenário ideal para a apreciação das consequências locais de processos transnacionais sistêmicos cujas camadas 
se encontram depositadas em todos os níveis da organização social tal como descrita no diário de Maria Eugénia. É nesse sentido que a abordagem nuançada que Rainhas da Noite dá à história do colonialismo em Moçambique dá lugar a uma complexidade de posições e resulta num universo no qual nem todos os negros querem independência e nem todos os brancos estão do mesmo lado.

A representação da rivalidade entre potências europeias no espaço periférico da colônia - posição que é ampliada pela escolha de um povoado-cenário que se encontra significantemente longe da capital de Moçambique - não se restringem à animosidade entre Maria Eugénia e Annemarie Simon, mas se multiplicam nas relações entre personagens que personificam outros setores daquela sociedade. Cunha, representante da polícia política e encarregado de observar e intervir a fim de proteger os interesses do regime português na região em que operava a mineradora estrangeira no romance, mantinha arquivos das atividades consideradas suspeitas tanto de moradores locais negros como de brancos não portugueses ou estrangeiros. A rebeldia expressa num comportamento inobservante das regras sociais e segregacionistas da região por parte de Suzanne Clijsters, outra senhora belga casada com um alto funcionário estrangeiro da mineradora, também constituiu, 
no romance, objeto investigação pelo regime português tal como comprovam arquivos oficiais encontrados décadas mais tade, numa caixa empoeirada e esquecida no Arquivo Nacional, pelo narrador-editor. Suzanne usava o tempo e recursos conferidos pelo privilégio da sua branquitude para, propositalmente, cruzar os limites do comportamento prescrito pela administração colonial como forma de afrontar diretamente a autoridade da sua compatriota, esposa do diretor da mineradora. Tal como o romance revela mais tarde, apesar do desprezo do inspetor pela presença dos belgas no território - "estravasados do Congo e sempre dispostos a provocar dores de cabeça a quem tinha que zelar pelas coisas" (BORGES COELHO, 2013 p.98; grifos do autor) - o controle que Annemarie exercia sobre a vida social dos empregados da companhia era endossado por Cunha, que detinha os meios de violência necessários para punir qualquer má conduta que escapasse à teia de soft power tecida pelos tentáculos de Annemarie Simon, a quem Maria Eugénia confere numerosas metáforas aracnídeas em seu diário. Esta aliança mantinha uma imagem sólida e inabalável da branquitude como forma de reificar seu poder e impor a ordem racial que subjazia a exploração colonial do continente africano.

Ainda que brancos fossem objeto de investigação e ação da polícia colonial no romance, vigilância 
e a intervenção colonial não aconteciam da mesma forma nos dois lados do abismo racial. É importante desatacar que na sua representação literária das relações complexas e estratificadas entre negros e brancos, locais, portugueses e outros estrangeiros na então colônia, Borges Coelho não aquiesce as falácias do discurso lusotropicalista nem incorre no mito da relativa benevolência do colonialismo português. Enquanto que o castigo às transgressões de Suzanne consistiram em nada além do seu retorno obrigatório para a Europa, antecedido por idílicas férias na cidade litorânea da Beira, a desobediência dos negros era punida através de prisão e surras mesmo quando sua suposta transgressão consistia simplesmente em obedecer as ordem dos seus senhores brancos tal como eram obrigados a fazer pelo mesmo regime que os viria punir mais tarde por isso. Desta maneira, a crescente simpatia que Maria Eugénia passou a nutrir por seu empregado, Travessa Chassafar, e o desenvolvimento de uma curta e tácia amizade entre os dois, não são excepcionais pois se enquadram justamente no horizonte de possibilidades de relações previsto pelo sistema colonial naquele ambiente. Longe de constituir uma representação romântica das possibilidades sociais durante o colonialismo, o ponto da representação desse tipo de associação entende-se ser o de trazer a lume parte da multiplicidade de relações possíveis, dentro do aparato social-ad- 
ministrativo colonial, incluindo graus de solidariedade interracial e alianças ocasionais. Isto é algo que Maria Eugénia custa a entender, sendo somente após ela ter seus próprios privilégios em Moatize limitador por Annemarie que ela passa a perceber o número ainda maior de concessões que aqueles menos privilegiados que ela tinham que fazer para poderem sobreviver.

É desta maneira que a pequena vila de Moatize se torna, no ramance, um lugar de encontros no qual as potências portuguesa e belga negociam suas relações produtivas no capitalismo colonial. 0 impacto dessas relações na população local, além do ambiente da mineradora e seus empregados (brancos e negros) é representada pelo caso do chefe M'Boola que, depois de ter sido nomeado régulo pela administração colonial, tinha como dever fazer com que sua comunidade obedecesse as resoluções portuguesas mesmo que em detrimento do seu bem-estar. Ainda que de forma diferente, essas negociações também regem as rotinas das vidas profissionais e pessoais do alto escalão da mineradora, tal como revelado pelo diário de Maria Eugénia. As ações de cada personagem no romance são limitadas pelo seu nível de privilégio. No ambiente social, e em certa medida também doméstico, do pessoal branco da mineradora Annemarie Simon manda e Maria Eugénia obedece. Enquanto 
à Suzanne Clijsters é permitido desafiar o poderio de sua compatriota, essa possibilidade é terminantemente negada à colona portuguesa. Fora dos limites do complexo residencial, entretanto, o poder concentra-se nas mãos do inspetor Cunha, que é mais tolerante com as transgressões de sua compatriota portuguesa do que de Suzanne. A população negra, nativa da região, só pode interagir com os estrangeiros belgas no tocante às suas funções na mineradora e sua coerção pelo uso da violência pode apenas ser praticado somente pelo representante do poder colonial, Cunha.

Em termos de temática, este romance de Borges Coelho captura, de fato, aspectos pouco conhecidos e discutidos do colonialismo português. Por apresentar a hierarquia geopolítica entre atores centrais do colonialismo através da representação do impacto dessa hierarquia sistêmica no ambiente da colônia, o autor cria uma mundo particular cuja arquitetura geográfica e social remetem ao sistema-mundial dentro do qual estão inseridos. Rainhas da Noite habilmente expõe a natureza relacional de poder durante o colonialismo português, o que torna o romance histórico, nacional e pós-colonial assim como faz dele também literatura-mundial, visto que transforma interconectadas narrativas subjetivas numa forma literária capaz de exprimir as complexas redes de poder que 
promovem e perpetuam a desigualdade em que se baseiam.

Por uma estética mundial da memória pós-colonial

A relação intrínseca entre memória e condição pós-colonial é uma sobre a qual tive a oportunidade de explorar em outra oportunidade (SANTOS, 2019). Começando por reconhecer que a memória está inscrita no tecido da literatura pós-colonial, haja vista seu compromisso em identificar e expor a continuação de características econômicas e sociais herdadas do colonialismo, naquela ocasião meu argumento foi o de que a estética da memória usada por José Eduardo Agualusa em Teoria Geral do Esquecimento (2012) é relevante por permitir o destaque de diferentes fases da longue durée das sociedades pós-coloniais. A ficção de Agualusa explora as políticas de celebração e esquecimento no âmbito da memória cultural num período que se estende sobre quase três décadas da história recente de Angola e, com isso, ele move a discussão da memória pós-colonial para além do paradigma binário da pós-colônia como um lugar definido apenas pelos traumas da crise resultante das ambivalentes relações entre colonizados e colonizadores, tal como proposto por Leela Gandhi em seu estudo sobre memória pós-colonial (1998, p.7-11). 
O foco na memória de um período histórico que começa com a independência de Angola traz à tona o fato de que complexas estruturas sistêmicas do país expressam arraigadas práticas coloniais, perpetuando, assim, sua lógica para muito além da expulsão do colonizador. Da mesma forma, o comentário que o romance propõe acerca das práticas de memorialização cultural - seja elas nas esferas institucionais ou privadas - destaca ainda mais o papel da memória em sociedades pós-coloniais, o que torna sua estética num importante aspecto a partir do qual é possível compreender o desenvolvimento dessas sociedades.

De maneira análoga àquilo que se observa no romance de Agualusa, Rainhas da Noite é organizado de maneira a chamar atenção tanto à memória quanto sua institucionalização. No que vai além de um retrato das dicotomias coloniais e aborda a história pós-colonial de Moçambique, o romance registra a condição pós-colonial na sua intrínseca natureza dinâmica, conferida por um afastamento temporal do colonialismo que combinado à sua permanência em termos de memória, costumes, estruturas, etc., que constituem a pós-colonia como um espaço de tempo enredado - ou entangled time - (MBEMBE, 2001, p.16-18). A ligação entre presente e passado é estabelecida desde o início do a história, quando da tentativa frustrada do narrado de adquirir uma cópia 
usada da Ilha de Próspero (1972) de Rui Knopfli que culmina na sua aquisição do diário de Maria Eugénia. 0 romance, portanto, tem início com a subversão da nostalgia por um tempo de luta que hoje já faz parte da memória cultural sancionada pelas instituições de seu país. "Há muito tempo que procurava aquela edição profusamente ilustrada [...] com um sabor de despedida e presságios, cuja carga trágica não conseguiria hoje despertar mais quem um sorriso. O que o tempo faz!" (BORGES COELHO, 2013, p.1415). Depois de pagar um preço que julgava excessivo pelo seu prazer nostálgico, o narrador recebem, como brinde, um testemunho pessoal e marginal das últimas décadas do colonialismo que irá, mais tarde, pôr à prova a própria concepção de verdade histórica da personagem.

Os capítulos do romance constituem, eles mesmos, pontos de intersecção entre passado e presente nos quais cada segmento dos relatos de Maria Eugénia compelem o narrador à uma busca pela verdade que combina sua entrevistas com Chassafar à múltiplas visitas aos arquivos públicos do país, localizados na capital. Na medida em que o romance avança, a jornada que se inicia com uma declaração de compromisso com a verdade - "Além disso, interessavam-me factos, não obscuras interpretações" (BORGES COELHO, 2013, p.151) - converte-se, gradualmente, 
num exercício desconstrutivo. Quanto mais o narrador visita os arquivos, menos o narrador consegue distinguir entre a figura do arquivista que o assiste e a de Chassafar, visto que as funções de guardiões da memória de ambas personagens passam a se confundir. Isso se dá porque, conforme o narrador oscila entre os domínios da memória pública e privada, sua percepção da verdade se altera significantemente. Assim, quanto mais o narrador verifica veracidade de informações históricas e geográficas descritas no diário, mais cresce sua suspeita sobre versões de fatos históricos disseminadas ao público pelo arquivo nacional. No final da história o narrador, agora completamente transformado por sua jornada presente pelo passado, se mostra completamente convencido do valor histórico das recordações pessoais:

De facto, por que razão se guardariam apenas documentos oficiais, negligenciando-se os de natureza privada? Será que o que é público tem mais valor? Se aproxima mais da verdade? A minha teoria dizia que não, e por diversas razões. Desde logo porque os papéis públicos são moldados por conveniências, não pela verdade. Aquilo que o ogre grotesco e cego pretende com o registro de suas actividades é deixar de si uma imagem conveniente para as gerações vindouras, uma imagem que, na sua perspectiva perversa e sonsa, lhe adoça a fama. Já os papéis pesso- 
ais - descontados os casos de dissimulação em que se pretende passar por privado o que é feito desde o início para ser público -, são testemunhos da luta que temos connosco próprios. Haverá luta mais verdadeira do que essa? Ali estava o carderno de Maria Eugénia Murilo para o comprovar! (BORGES COELHO, 2013, p.286-7)

O ápice deste processo é detalhado nas páginas subsequentes onde um narrado à beira do desespero, cegado como estava pela sua obsessão com a narrativa de Maria Eugénia, suborna o funcionário do arquivo nacional para ganhar acesso aos bastidores da instituição a fim de procurar por outros diários como aquele, na esperança de encontrar ainda mais perspectivas autênticas sobre os fatos históricos do país. No delirante trecho seguinte, temos uma descrição febril do que o narrador encontra ao ser levado pelo arquivista ao submundo da história. Nas traseiras e nos andares inferiores do edifício, tem lugar uma contínua e feroz luta entre arquivistas e ratazanas especializadas em devorar as enormes pilhas de documentos originais, chegados das várias províncias do país, que constituem autênticos pedaços de história. 0 que se consegue salvar do apetite das ratazanas e outros insetos no subsolo do prédio é, então, enviado ao primeiro andar "para ser reagrupad[o] segundo os critérios oficiais em vigor num rítimo que "faz 
lembrar um antiga fábrica em pleno funcionamento" (BORGES COELHO, 2013, p.290-291), e não deixa dúvidas da natureza artificial das versões da história dadas a ingênuos visitantes, tais como nosso narrador, na organizada e silenciosa sala de leitura.

A subordinação política da memória cultural do país representada em Rainhas da Noite já foi objeto de análise do próprio autor, na sua capacidade como historiador e acadêmico. No seu ensaio "Writing in a changing world: The difficult relationship with reality", publicado no mesmo ano do romance, Borges Coelho levanta uma série de questões relacionadas à autonomia da escrita literária em Moçambique. Visto paralelamente à outros países que também foram, no passado, colônias portuguesas, o autor considera o impacto das heranças coloniais e socialistas, bem como o impacto do neoliberalismo e da guerra civil para afirmar que a literatura ainda carece da liberdade e autonomia de que precisa para cumprir com seu papel na memória cultural do país. Para Borges Coelho, o maior desafio da literatura moçambicana atual é mudar do paradigma nacionalista para o paradigma democrático. Segundo o autor:

0 papel da literatura, assim como o de outras artes, continua a ser visto como apoiar e celebrar a política. Isto é, naturalmente, não apenas por causa do autoritarismo da polí- 
tica, mas também pela fragilidade do sistema literário, com o seu número extremamente reduzido de leitores e escritores, de editores quase inexistentes, livros muito caros, etc. Tudo isto cria grande promiscuidade entre as esferas política e literária, assim como uma situação na qual apenas alguns livros não patricionados cheguem a ver a luz do dia". (BORGES COELHO, 2013, p.27; tradução nossa)

Como consequência, vemos como Borges Coelho estrutura Rainhas da Noite como uma resposta direta à uma situação moçambicana que é paradigmática, mas que não é, de forma alguma, desligada da realidade de outros países periféricos que tem processos históricos paralelos como Angola. Sendo um dos poucos escritores moçambicanos que escapa àquilo que chama de promiscuidade entre as esferas política e literária, o autor cunha uma estética da memória que dialoga com a herança recente da condição pós-colonial em Moçambique. Colocadas em frutífera dialética, o tema e estética do romance funcionam em conjunto promovendo uma crítica da memória pós-colonial de proporções sistêmicas.

Em conclusão, Rainhas da Noite de João Paulo Borges Coelho constitui um romance exemplar por conter importantes elementos dos quais se é possível derivar uma estética literário-mundial da memória pós-colonial. 0 tratamento da história colonial na 
obra desconstrói a representação tradicional do colonialismo como um sistema exclusivamente fixo de dicotomias claras, recuperando complexas relações hierárquicas no sistema-mundial capitalista. Irrestritas à oposição binária entre colonizador e colonizado, os vários tipos de relações sociais possíveis nesse contexto também revelam elementos da estrutura mais ampla na qual se inserem, dividida em centro, semiperiferia e periferia. Desta maneira, o romance consegue reestruturar processos de subordinação, exclusão e exploração do período colonial de Moçambique na longue durée do capitalismo, que perdura como sistema econômico em vigor no país. 0 romance, portanto, propõe uma crítica que não perde força perante quaisquer versões convenientes da história do país. Por outro lado, a estrutura do romance, que problematiza o processo de institucionalização de memória cultural, investindo na perspectiva de sujeitos marginalizados como fonte história válida e denunciando controle ideológico, é, em si mesmo, um recurso narrativo mundial-literário. Aplicável não apenas à história de Moçambique, mas também às contradições de sociedades pós-coloniais periféricas de forma geral, tal como é o caso dos países africanos que fizeram parte do império colonial português, Rainhas da Noite fala de verdades que vão muito além dos limites convenientes da política nacional, pois aborda àquilo que é sistêmico e estrutural. 


\section{Referências}

AGUALUSA, José Eduardo. Teoria geral do esquecimento. Alfragide: Dom Quixote, 2012.

AGUALUSA, José Eduardo. A general theory of oblivion, trad. Daniel Hahn. London: Harvil Secker, 2015. BATA, Eduardo Jaime. Entre estatais e transnacionais, "quantos ais": efeitos espaciais dos Megaprojetos de mineração do carvão em Moatize, Moçambique. 565p. Tese (Doutorado em Geografia) - Universidade Federal de Goiás, 2018. Sibi - UFG.

BORGES COELHO, João Paulo. Escrita académica, escrita literária. In CALAFATE RIBEIRO M., e MENEZES, M. P., orgs. Moçambique das Palavras Escritas. Porto: Edições Afrontamento, 2008, p. 229-236.

BORGES COELHO, João Paulo. Rainhas da Noite. Lisboa: Caminho, 2013.

BORGES COELHO, João Paulo. Writing in a changing world: The difficult relationship with reality. Luso-Brazilian Review, n.50, v.2, p. 21-30, 2013.

BRUGIONI, Elena. O caderno, o velho e as três mulheres. Rainhas da Noite, um romance indiciário. Revista de Estudos Literários / Universidade de Coimbra, v.5, 2015, p.415-438.

BRUGIONI, Elena. Rainhas da Noite, um romamnce indiciário. In Khan, S., Souza, S., Simas-Almeida, L., Ferreira Gould, I.A. e Can, N.A. (orgs.). Visitas a João 
Paulo Borges Coelho: Leituras, diálogos e futuros. Lisboa: Edições Colibri, 2017, p.195-213.

CALAFATE RIBEIRO, Margarida. Mulheres, colonialismo, emancipação: uma leitura de Rainhas da Noite, João Paulo Borges Coelho. Mulemba / UFF, Rio de Janeiro, n.18, v.10, p.57-68, 2018.

CAN, Nazir. Rainhas da Noite, Metamorfoses, n.14, v.2, 2017, p. 185-188.

CARVALHÃO BUESCU, Helena. Experiência do incomum e boa vizinhança: Literatura comparada e literatura-mundo. Porto: Porto Editora, 2013.

DAMROSCH, David. What is world literature? Princeton and Oxford: Princeton University Press, 2003.

FREIXO, Adriano de. As pressões internacionais e a crise do último império: A política colonial portuguesa nas décadas de 1950 e 1960. In: XXIV SIMPÓSIO NACIONAL DE HISTÓRIA, 2007, São Leopoldo. Anais. São Leopoldo, 2007. p.1-8.

GANDHI, Leela. Postcolonial theory: A critical introduction. Sydney: Allen \& Unwin, 1998.

GRAHAM, James, Michael Niblett and Sharae Deckard. Postcolonial Studies and World Literature, Journal of Postcolonial Writing, n.48, v.5, p. 465-471, 2012.

MBEMBE, Achille. On the postcolony. Berkeley: University of California Press, 2001.

NEWITT, Malyn. Portugal in the European and world history. London: Reaktion Books, 2009. 
SANTOS, Emanuelle. Memory and the contemporary postcolonial condition in José Eduardo Agualusa's A General Theory of Oblivion. In Göttsche, D. (org.). Memory and postcolonial studies: Synergies and new directions. Oxford, Bern: Peter Lang, 2019, p. 131-147. SOUZA, Sandra. "E tu, que achas tu de tudo isto?": Colonial women, memory and post-independence in João Paulo Borges Coelho's Rainhas da Noite. Gragoatá / UFF, Niterói, n.41, p.830-849, 2016.

WALLERSTEIN, Immanuel. O Sistema mundial moderno: A agricultura capitalista e as origens da economia-mundo europeia no século XVI. Trad. Carlos Leite, Fátima Martins e Joel de Lisboa. Porto: Edições Afrontamento, 1974.

WARWICK RESEARCH COLLECTIVE (WReC). Combined and Uneven Development: Towards a New Theory of World-Literature. Liverpool: Liverpool University Press, 2015. 